\title{
A multi-institutional and interdisciplinary approach to the assessment of vulnerability and adaptation to climate change in the Peruvian Central Andes: problems and prospects
}

\author{
A. G. Martínez ${ }^{1}$, K. Takahashi ${ }^{2}$, E. Núñez ${ }^{3}$, Y. Silva ${ }^{1}$, G. Trasmonte ${ }^{1}$, K. Mosquera ${ }^{1}$, and P. Lagos ${ }^{1}$ \\ ${ }^{1}$ Geophysical Institute of Peru, Lima, Peru \\ ${ }^{2}$ NOAA/GFDL, Princeton, New Jersey, USA \\ ${ }^{3}$ Yanapai, Huancayo, Peru
}

Received: 15 June 2007 - Revised: 29 September 2007 - Accepted: 5 October 2007 - Published: 10 April 2008

\begin{abstract}
A local integrated assessment of the vulnerability and adaptation to climate change in the Mantaro River Basin, located in Peruvian Central Andes, was developed between years 2003 to 2005 . In this paper we present some lessons learned during the development of this study, emphasizing the multi-institutional and interdisciplinary efforts, briefly showing the methodological aspects, and pointing out the main problems found.
\end{abstract}

\section{Introduction}

One of the main global environmental changes that has been experiencing by the planet in the last few decades is climate change, which is largely the result of anthropogenic greenhouse gases emissions into the atmosphere (IPCC WG1, 2007), and the consequent set of impacts on the biosphere (IPCC WG2, 2007).

Although it is recognized that the studies of the consequences of climate change for human activities must be developed on regional and local scales, and in interdisciplinary ways that combine, interpret and communicate knowledge of diverse scientific disciplines (Rotmans and Dowlatabadi, 1998), concrete examples of studies of this nature are rarely found, partly because the methodologies for this type of study are in an incipient stage.

Motivated by this consideration, in this article we present experiences and lessons learned during the development of the pilot study "Local Integrated Assessment of the Mantaro River Basin", which was developed fundamentally as an interdisciplinary and interinstitutional work between the years 2003 and 2005 by the Geophysical Institute of Peru (IGP) in coordination with the National Council of the Environment (CONAM).

The central objective of the study was to systematize and to extend the knowledge about climate change in the Mantaro River Basin, and to evaluate the climatic, physical and social aspects of its vulnerability to this change, as well as to identify viable options of adaptation in agriculture, hydroelectric energy generation and health sectors, in order to be incorporated in the local and regional development plans.

Future scenarios were generated for 50 years into the future, which was considered a long enough time that the climate change signal would be significant, but short enough that they would be relevant to the stakeholders that currently inhabit or operate in the basin.

\section{Study area}

The Mantaro River Basin, located in the Peruvian Central Andes, has great socioeconomic importance for generating, through its hydroelectric power stations, nearly $35 \%$ of the electrical energy of the country, for being the main source of agricultural products for Lima (IGP, 2005a), and for having a population that surpasses the 1.2 million inhabitants.

The discharge of the Mantaro River depends on the precipitation in the whole river basin, of the level of Lake Junín and the lagoons located at the foot of the mountains in the Western and Eastern cordilleras. The glaciers on some of these mountains are also important water reservoirs for the Andean societies that live on their foothills, and are particularly sensitive to the evolution of the climate change (Pouyaud et al., 1995).

Correspondence to: A. G. Martínez

(martinez@geo.igp.gob.pe)

Published by Copernicus Publications on behalf of the European Geosciences Union. 


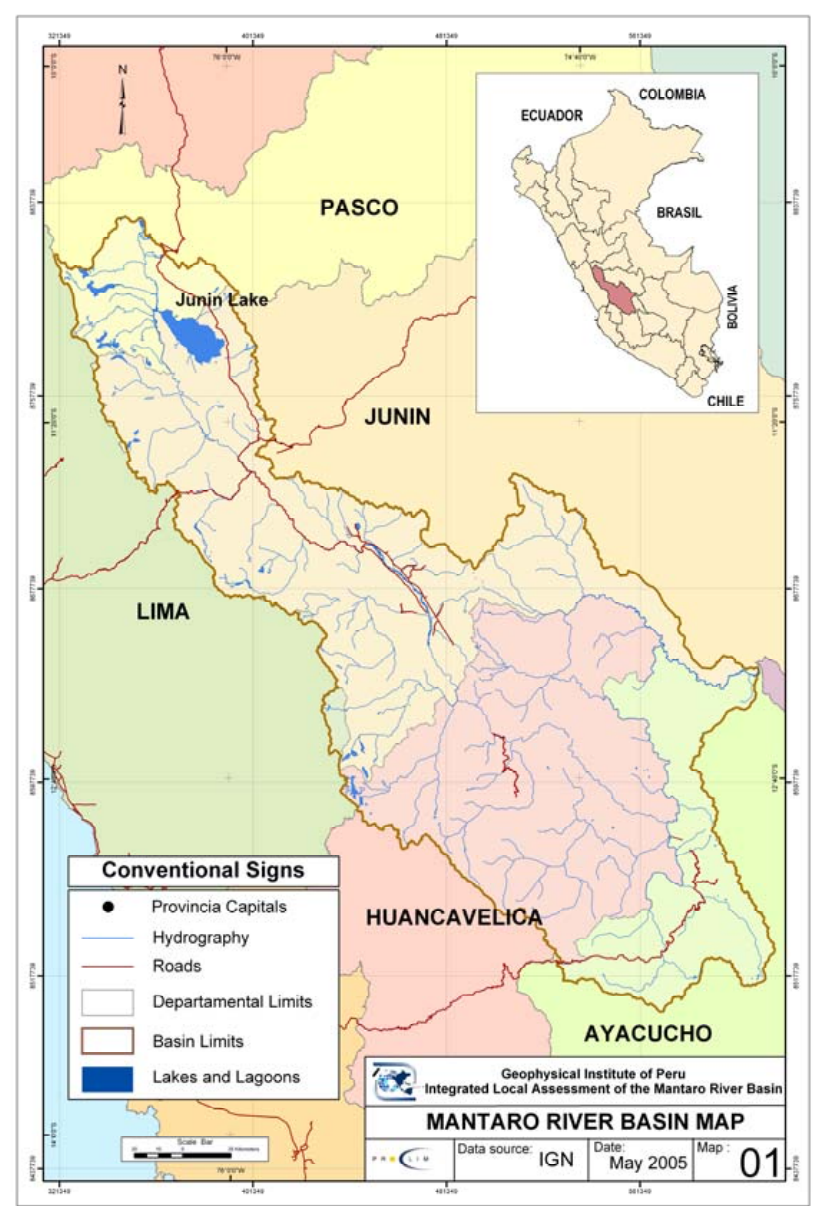

Fig. 1. Mantaro River Basin map.

\section{Methodology}

The methodology used in the study is outlined in Fig. 1. The first step for the development of the study was the determination of a physical and socially relevant baseline based on the diagnosis of the present state of the river basin. This diagnosis (IGP, 2005a) provided an integral landscape of the river basin reality, not only from the biophysical and socioeconomical perspective, but also cultural (e.g. the ancestral and present perception of the environmental reality by the population). The elaboration of this diagnosis involved integrating information that was scattered among several institutions, along with the information obtained from surveys and participative workshops. The workshops, however, were not just a means of gathering information but were fundamental for the design of the data collection methodology, which benefited greatly from the diversity in expertise of the professionals from the different participating institutions. The input of these professionals into the design of the surveys led to the inclusion of a larger set of themes than previously envisioned, such as the occurrence of geodynamical and atmo-

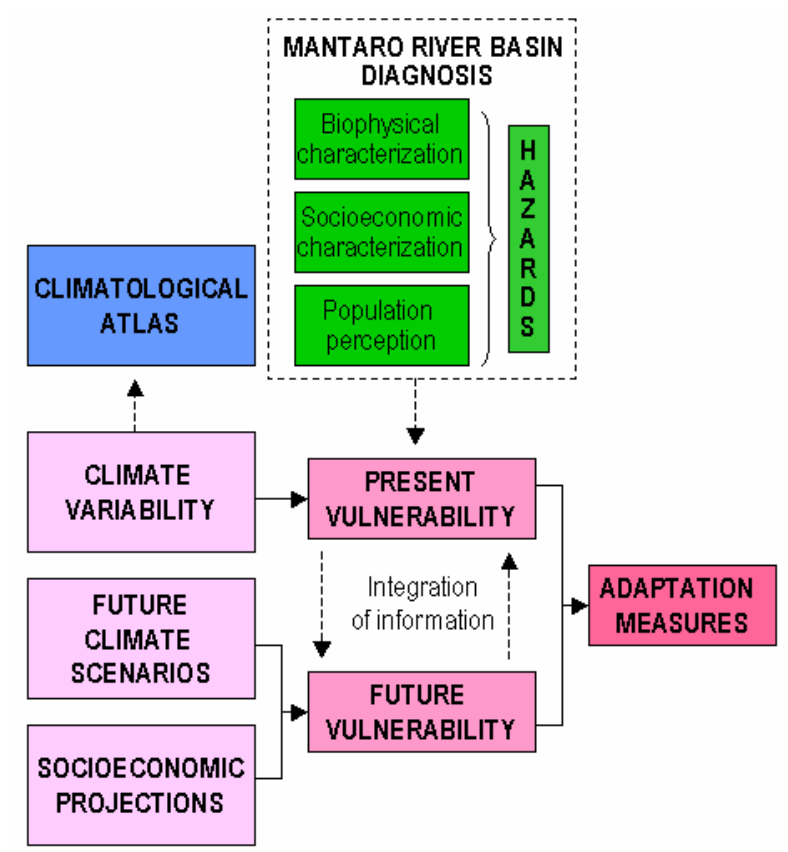

Fig. 2. Methodology flow chart used in the Local Integrated Assessment in the Mantaro River Basin study.

spheric phenomena and changes in water resources, biodiversity, and agricultural productivity. For example, following recommendations from social scientists from NGOs working on issues of regional development, information was collected on ancestral knowledge in the cultivation and consumption of native plant species, traditional agricultural practices, etc. This information was referred as "guardians of the past".

The diagnosis allowed the identification of the main climate hazards to which the population of the basin is exposed (droughts, frosts and external geodynamical processes). This information was complemented with a detailed study of the climate variability in the river basin, and with the generation of future climate scenarios and socioeconomical projections for the year 2050, which provided the basis for the analysis of present and future vulnerability (IGP, 2005b).

The vulnerability analysis was focused on three economic sectors that were selected in workshops with the participation of representatives from several collaborating institutions. The results of this analysis in turn provided the basis for the elaboration of maps of climate hazards and for the design of measures of adaptation to the effects of the climate change, which would increase the resilience of the population of the basin (IGP, 2005b). 


\section{A multi-institutional and interdisciplinary approach to the local integrated assessment in the Mantaro River Basin}

The fundamental tools of this study were the participative workshops with local institutions and grassroot associations of the basin, which allowed the incorporation of the knowledge from the stakeholders on the reality of the basin into the process of making decisions about the development of the study, such as the prioritization of socioeconomical sectors (agriculture, hydroelectric energy generation and health), the division of the basin into zones of study, the integration of activities, etc.

More than 50 institutions were invited to participate, including public institutions, non- governmental organizations (NGOs), public and private companies, universities, local and regional governments and grassroot organizations. Effective support throughout the study was given by approximately 25 institutions, which became the "collaborating institutions" of the study.

The public institutions and NGOs associated with - to larger or smaller degree - the agricultural sector, were the most actively involved and those that contributed the most to the study. This situation was probably motivated by the high sensitivity of the agriculture sector (which is mostly done without irrigation) to climate variability - and a high dependence on precipitation for water and motivated by the high incidence of plagues in abnormally warm years, which in turn directly affects the sources of economic income and food of a large part of the population.

On the other hand, the participation of private (mining, etc.), and public (hydroelectric energy companies, potable water municipal company, etc.) companies was practically null. This was probably because the former did not consider the issues that were addressed by the study important for the development of their activities, while the latter are barely affected by climate variability, in addition to having a short term vision in their management.

An illustrative example of the insensitivity of the public companies to climate variability was given by the strong 2003-2004 drought, during which the level of Lake Junin, the main reservoir, was reduced by nearly $40 \%$, yet the energy production generated by Electroperú company was essentially unaffected (COES, 2007), because the company has an operative strategy of dams and lagoons unloading and can play with marginal prices of energy, situation that makes the company resilient within tolerable limits to these variations.

Similarly, the same drought affected the potable water supply (daily hours of service) and therefore the population, but did not affect the municipal water company that provides it, since the price the users pay for the service is approximately independent of their consumption on water (SEDAM, 2005). In fact, an effort was made for getting engineers from the company involved in the project, but they refused arguing that the production and distribution of water, their primary concern, was unrelated to glaciers and would not be affected by climate change. Rather than an indication of ignorance, this statement was most likely motivated by a reluctance to getting involved in an issue that is not of immediate concern to them.

The participation of local and regional governments was limited, largely due to the lack of diffusion of information that climate change issues had at the beginning of the study, and to the work priorities of most authorities being focused on other immediate issues such as transport, citizen security, etc. The exceptions were the regional governments of Junin and Huancavelica, probably because both already had several years working on issues related to the environment, and had pre-existing working groups on water, contamination, forest resources, etc., so their participation in the study occurred naturally.

For the development of the study, two working groups were formed. The first group was in charge of the study of climate variability and change and was formed mainly by a small group of researchers from the Geophysical Institute of Peru, specialized in different physical sciences. The second group, formed by approximately 30 researchers of the collaborating institutions, from diverse social and agricultural disciplines, participated in the analysis of the present and future vulnerability, as well as in the formulation of adaptation proposals (IGP, 2005b).

The researchers of the collaborative institutions participated in the study without any additional financial incentive. Instead, their participation in the workshops and working meetings was facilitated by the provision of transport, meals, working material, etc. The exception was the payment made to an NGO for its participation in the development of the report on health and the links between this sector and climate change. However, this additional monetary support turned out to have been an error, since the studies on this sector were not any more deserving of extra support than the other two prioritized sectors, and it jeopardized the feeling of equity and the good relations with the other collaborating institutions.

Although the necessary interaction between specialists of different disciplines and institutions doubtlessly enriched the study, this was not easy to achieve since their different backgrounds led to serious difficulties of understanding among the researchers. This problem was eventually overcome thanks to the numerous workshops and working meetings in which the terminology and methodology used in the study were homogenized. A clear recurrent example of the differences among the disciplines, was the difficulty in understanding the intrinsic uncertainties in the future climate scenarios. In particular, the researchers in the social sciences expected an accuracy from these scenarios that is not possible to obtain with any current method or present-day models.

An important achievement related to the previous point was to ensure the participation of the same researchers from each institution by making formal requests to their respec- 
tive institutional authorities, and to obtain their "loyalty" to the study and the group, using some simple incentive strategies that emerged throughout the study: uncostly training workshops on subjects direct and indirectly related to climate change, promotion of exchange of information, giving a certificate in recognition of their participation at the end of the two years, and crediting their participation in the research as individuals in the final reports of the study (IGP, 2005a, b).

In addition, during the study, an "open participation" was allowed, i.e. researchers or institutions were freely allowed to join the research group even during advanced stages of the study. Although this often meant making tedious summaries of issues already discussed and decided to the new members of the group, their subseequent contribution was beneficial for the study in the long run and also gave the group a strong sense of openness not experienced in other studies.

The lack of coordination between institutions and the administrative obstacles for the signing of cooperative agreements and for information exchanges, etc. were constant, mainly for public institutions. This situation was partially overcome throughout the study, but it caused delays in the initial stages of the study.

An unforeseen outcome of the study was the formation of a technical team for climate change integrated by the institutions that participated in the study, This technical team was formed with support from the Regional Government of Junin and its main objective is to incorporate the issues related to climate change in the development plans at the provincial and regional levels, as well as to elaborate projects for the study of vulnerability and adaptation to climate change and to develop adaptation measures to climate change.

\section{Conclusions}

In this concrete example of managing a local integrated assessment of the vulnerability and adaptation to climate change in the Peruvian Central Andes, it was verified that the multi-institutional and interdisciplinary participatory efforts are a powerful approach to undertaking such assessments at the local level.

Working with multiple institutions - private and public is not free of problems, but is clear that some simple strategies such as the recognition of contributions of the individuas involved in the study, the training, and the exchange of information, can enormously facilitate the participation of institutions in the future.

Acknowledgements. The authors thanks the National Council of Environment CONAM and the Real Embassy of the Netherlands for their support in the development of the "Local Integrated Assessment in the Mantaro River Basin" study.

$\mathrm{K}$. Takahashi is supported by a NOAA Climate and Global Change postdoctoral fellowship.
Edited by: P. Fabian

Reviewed by: two anonymous referees

\section{References}

Comité de Operación Económica del Sistema Interconectado Nacional COES: Estadísticas Mensuales, in: http://www.coes.org. pe/coes/index.asp, 2007.

Instituto Geofísico del Perú: Diagnóstico de la cuenca del río Mantaro bajo la visión de cambio climático, Fondo Editorial CONAM. Lima, Perú, 2005a.

Instituto Geofísico del Perú: Vulnerabilidad y adaptación al cambio climático en la cuenca del río Mantaro, Fondo Editorial CONAM. Lima, Perú, 2005b.

IPCC WG1: Climate Change 2007: The Physical Science Basis, Summary for Policy Makers, Contribution of Working Group I to the Fourth Assessment Report of the Intergovernmental Panel on Climate Change, 2007.

IPCC WG2: Climate Change 2007: Impacts, Adaptation and Vulnerability. Summary for Policy Makers, Contribution of Working Group II to the Fourth Assessment Report of the Intergovernmental Panel on Climate Change, 2007.

Martínez, A. G., Núñez, E., Silva, Y., Takahashi, K., Trasmonte, G., Mosquera, K., and Lagos, P.: Vulnerability and adaptation to climate change in the Peruvian Central Andes: Results of a Pilot Study, in: International Conference on Southern Hemisphere Meteorology and Oceanography (ICSHMO), Foz do Iguaçu. Proceedings, São José dos Campos, INPE, CD-ROM ISBN 85-1700023-4, 297-305, 2006.

Pouyaud, B., Francou, B., and Ribstein, P.: La red monitoreo glacio-hidrológico de ORSTOM y de sus contrapartes en Bolivia, Perú y Ecuador: una herramienta para el estudio del recalentamiento global y de sus consecuencias en los trópicos, in: Aguas, glaciares y cambios climáticos en los Andes tropicales, edited by: IFEA, IRD, ORSTOM, UMSA, SENAMHI y el Comité Nacional para el Programa Hidrológico Internacional, La Paz, Bolivia, 229-238, 1995.

Rotmans, J. and Dowlatabadi, H.: Integrated assessment modelling, in: Human Choice and Climate Change, Vol. 3, The tools for Policy Analysis, edited by: Rayneer, S. and Malone, E. L., Batelle Press, Columbus, OH, EE.UU, 1998.

SEDAM: Cuál es la realidad del agua en Huancayo?, Informative, Huancayo, Peru, 2005.

Turner, B. L., Kasperson, R. E., Matson, P. A., McCarthy, J. J., Correll, R. W., Christensen, L., Eckley, N., Kasperson, J. X., Luers, A., Martello, M. L., Polsky, C., Pulsipher, A., and Schiller, A.: Illustrating the coupled human-environment system for vulnerability analysis: Three case studies, Proceedings of the National Academy of Sciences of the United States of America, PNAS, 100, 14, 8074-8079, 2003. 